Accepted for publication by Water Resources Research

\title{
OBSERVATIONS OF A POTENTIAL SIZE-EFFECT IN EXPERIMENTAL DETERMINATION OF THE HYDRAULIC PROPERTIES OF FRACTURES
}

\author{
P. A. Witherspoon, C. H. Amick, ${ }^{1}$ U. E. Gale, ${ }^{2}$ and K. Iwai ${ }^{3}$ \\ Departmenc of Materials Science and Mineral Engineering \\ and \\ Lawrence Berkeley Laboratory \\ University of California \\ Berkeley, Caiifornia
}

May 1979

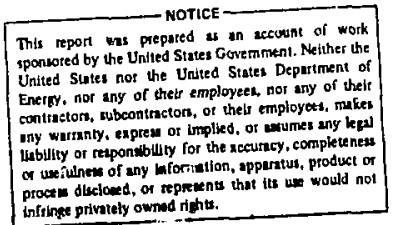

$1_{\text {Now with Liftech Consultants, Inc., Oakland, California. }}$

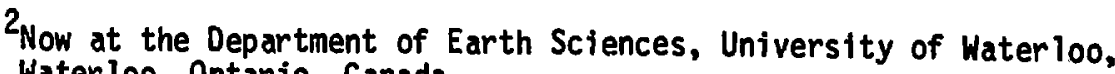
Waterloo, Ontario, Canada.

3 Now with Nakano-Corporation, Niigatashi, Japan. 
PREFACE

This report is one of a series documenting the results of the Swedish-American cooperative research program in which the cooperating scientists explore the geological, geophysical, hydrological, geochemical, and structural effects anticipated from the use of a large crystalline rock mass as a geologic repository for nuclear waste. This program has been sponsored by the Swedish Nuclear Power Utilities through the Swedish Nuclear Fuel Supply Company (SKBF), and the U.S. Departmer:t of Energy (DOE) through the Lawrence Berkeley Laboratory (LBL).

The principal investigators are L. B. Nilsson and 0. Degerman for SKBF, and N. G. W. Cook, P. A. Witierspoon, and J. E. Gale for LBL. Other participants will appear as authors of the individual reports.

Previously published technical reports are listed below.

1. Swedish-American Cooperative Program on Radioactive Waste Storage in Mined Caverns by P. A. Witherspoon and 0. Degerman. (LBL-7049, SAC-01).

2. Large Scale Permeability Test of the Granite in the Stripa Mine and Thermal Conductivity Test by Lars Lundstrom and Haken Sti17e. (LBL-7052, SAC-02).

3. The Mechanical Properties of the Stripa Granite by Graham Swan. (LBL-7074, SAC-03).

4. Stress Measurements in the Stripa Granite by Hans Carlsson. (LBL-7078, SAC-04).

5. Borehole Orilling and Related Activities at the Stripa Mine by P. J. Kurfurst, T. Hugo-Persson, and G. Rudolph. (LBL-7080, SAC-05).

6. A Pilot Heater Test in the Stripa Granite by Hans Carlsson. (LB!-7086, SAC-06).

7. An Analysis of Measured Values for the State of Stress in the Earth's Crust by Dennis B. Jamison and Neville G. W. Cook. (LBL-7071, SAC-07).

8. Mining Methods Used in the Underground Tunnels and Test Rooms at Stripa by B. Andersson and P. A. Halen. (LBL-7081, SAC-D8).

9. Theoretical Temperature Fields for the Stripa Heater Project by T. Chan, Nevifle G. W. Cook, and C. F. Tsang. (LEL-7082, SAC-09). 
10. Mechanical and Thermal Design Considerations for Radio- active W-ste Repositories in Hard Rock. Part I: An Appraisal of Hard Rock for Potential Underground Repositories of Radioact ive hastes by Neville G. W. Cook; Part II: In Situ Heating Experiments in Hard Rock: The ir Objectives and Desigin by Neville G. W. Cook and P. A. Witherspoon. (LBL-7073, SAC-10).

11. Full-Scale and Time-Scale Heating Experiments at Stripa: Freliminary Results by Neville G.W. Cook and Michael Hood. (LBL-7072, SAC11).

12. Geochemistry and I sotope Hydrology of Groundwaters in the Stripa Granite: Results and Preliminary Interpretation by $P_{\text {. Fritz, }}$ J.F. Barker, and J.E. Gale. (LBL-8285, SAC-IZ).

13. Electrical Heaters for Thermo-mechanical Tests at the Stripa Mine by R. H. Burleigh et a.. (LBL-7063, SAC-13).

14. Data Acquisition, Handling, and Display for the Heater Experiments at St.ripa by Maurice B. McEvoy (LBL-7062, SAC-14).

15. An Approach to the Fracture Hydrology at Stripa: Prel iminary Results by J. E. Gale and P. A. Witherspoon. (LBL-7079, SAC-15).

16. Preliminary Report on Geophysical and Mechanical Borehole Measurements at Stripa by P. Nelson, B. PauTsson, R. Rachiele, L. Andersson, T. Schrauf, N. Hustrulid, 0. Duran, and K. A. Magnusson. (LBL-8280, SAC-16). 
TABLE OF CONTENTS

Fage

NOMENCLATURE .......................... vi

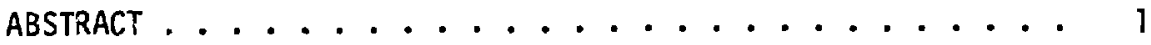

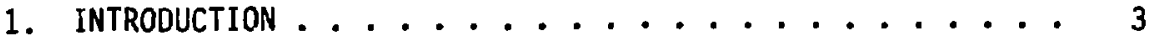

2. EQUATIONS FOR FRACTURE CONDUCTIVITY. ........ 3

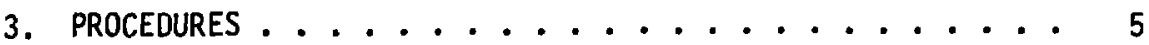

4. DISCUSSION OF RESULTS. .............. 10

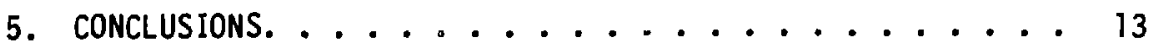

6. ACKNOWLEDGMENTS ............................... 14

7. REFERENCES ............................. 14

\section{LIST OF FIGURES}

1. Radial flow from a well into a horizontz? fracture . . . 4

2. Linear flow in a vertical fracture......... 5

3. Radial flow model for laboratory experiments on a horizontal fracture ............. 7

4. Large-dianeter core ready for assembly in triaxial cell . 8

5. Variation of hydraulic conductivity in a fracture with increasing stress for three different-size rock samples . II

6. Effect of contact area on fracture permeability .... 12 
NOMENCLATURE

b

D

9

h

$k_{f}$

$k_{f}$

L

Q

$r$

$\mu$

$\rho$ aperture half width

vertical length of fracture

acieleratiur of gravity

hydraulic head

fracture intrinsic permeabilit."

fracture hydraulic conductivity

horizontal length of fracture

flow rate

radial distance

fluid viscosity

fluid density
L

L

$1 . / T^{2}$

L

$L^{2}$

$L / T$

L

$L^{3} / T$

L

M/LT

$M / L^{3}$ 
ABSTRACT

In several recent investigations, experimental stuoies on the effect of normal stress on the hydratiic conductivity of a single fracture were made on three rock specimens ranging in cross-sectional area from $0.02 \mathrm{~m}^{2}$ to over $1.0 \mathrm{~m}^{2}$. At the maximum stress levels that could be attained ( 10 to $20 \mathrm{MPa}$ ), minimum values of the fracture hydraulic conductivity were not the same for each rock specimell. These minimum values increased with specimen size indicating that :he determination of fracture conductivity may be significantly influenced by a size effect. The implications of these results are important. Cores collected in the field are normally not larger than $0.15 \mathrm{~m}$ in diameter. However, the results of this work suggest that when this size core is used for laboratory investigations, the results may be non-conservative in that fracture permeabilities will be significantly lower than will be found in the field. If the results with an ultralarge core (0.95-m diameter) are more indicative of field conductivities for a fracture under stress, then further work is needed to determine optimum specimen size so that reliable results on flow in fractures under stress will be avallable. 


\section{INTRODUCTION}

Many geological sitliations of engineering importance require accurate determination of the hydraulic properties of rock. When this rock is fractured, the properties of the fractures must also be investigated. In certain applications, such as the underground storage of radioactive wastes, accuracy in the determination of the hydraulic properties is of greatest importance. In several recent investigations, experimental studies on the effect of stress on fracture permeability properties were made on rock specimens ranging in cross-sectional area from $0.02 \mathrm{~m}^{2}$ to over $1.0 \mathrm{~m}^{2}$ (Gale 1975; Iwai 1976; Witherspoon, Amick, and Gale 1977; Pratt et al. 1977). A comparison of results from these studies on stress-dependent fracture conductivity suggests that there may be an effect of sample size. If this is the case, there is an important problem in deciding what size rock specimens should be collected for laboratory investigations. The following will present the results of these preliminary studies.

\section{EQUATIONS FOR FRACTURE CONDUCTIVITY}

Equations describing fluid flow between two parallel plates have been derived by Polubarinova-Kochina (1962), Snow (1965), Louis (1969), Noorishad, Witherspoon, and Brekke (1971), Bear (1972), Gale (1975) and several other workers in the field of fracture flow. These authors have shown that the intrinsic permeability of a fracture with an aperture of $2 b$ is given by

$$
k_{f}=\frac{(2 b)^{2}}{12}
$$


and this may be converted to the hydraulic conductivity of a fracture by

$$
k_{f}=\frac{k_{f} \rho g}{\mu}=\frac{(2 b)^{2} \rho g}{12 \mu}
$$

If one has steady-state radial flow from a borehole into a horizontal fracture (as shown in Fig. 1) and the hydraulic he!ad drops from $h_{w}$ at the wellbore radius $r_{w}$ to $h_{e}$ at the outer radius $r_{e}$, then the injection rate, $Q$, may be determined from Darcy's $l$ aw and is given by:

$$
Q=\frac{2 \pi(2 b)^{3} \rho g\left(h_{w}-h_{e}\right)}{12 \mu \ln r_{e} / r_{w}}
$$

In laboratory investigations where the aperture is unknown, Eq. 3 can be used to solve for $2 b$ directly, since $a l l$ other parameters are measurable. The hydraulic conductivity can then be determined using Eq. 2 .

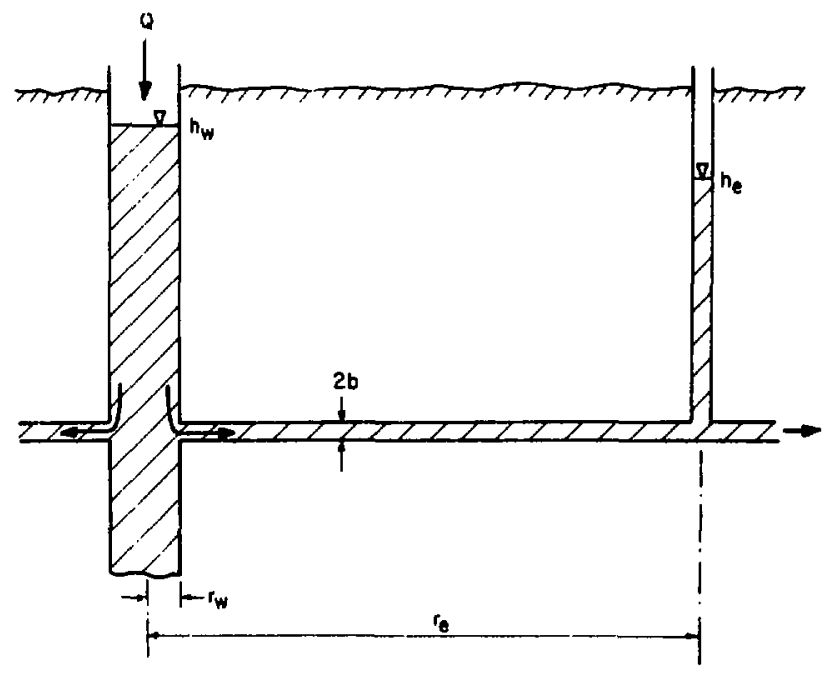

Fig. 1. Radial flow from a well into a horizontal fracture. (XBL 7811-12800) 
If one has steady-state linear fiow in a vertical fracture of extent $D$ (as shown in Fig. 2) and the hydraulic head drops from $h_{w}$ to $h_{e}$ over lengih $L$, then the flow rate, $Q$, may be determined from

$$
Q=\frac{(2 b)^{3} \rho g D\left(n_{w}-h_{Q}\right)}{12 \mu L}
$$

In experimental investigations, Eq. 4 can be used to solve for $2 b$, and Eq. 2 to solve for $K_{f}$.

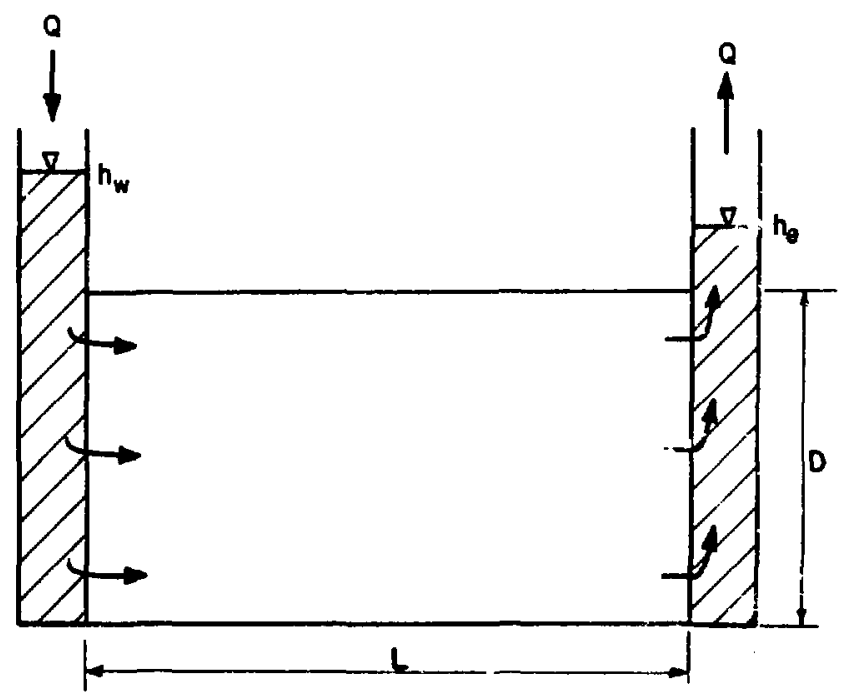

Fig. 2. Linear flow in a vertical fracture.

(XBL 7811-12801)

\section{PROCEDURES}

The main objective of these experiments was to investigate the nature of flow in natural rock fractures. This made it essential for the experiments to simulate fracture conditions as closely as possible. The laboratory tests (Gale 1975; Iwai 1976; Witherspoon, 
Amick, and Gale 1977) used an artificially induced tension crack to simulate a natural fracture. The in situ tests, which will be taken from the work of Pratt et al. (1977), used an existing fracture at a surface exposure. The apertures in both laboratory and field tests were controlled by changing the normal compressive load across the fracture.

The rock used in the laboratory experiments was identified by its supplier, the Cold Springs Granite Company, as Sierra White Granite. This granite is fine to medium grained with a uniform texture, and can be classified as a grayish white, muscovite-biotite, quartz monzonite, based upon thin section analysis (Gale 1975). Its unconfined compressive strength and Young's modulus are approximately $200 \mathrm{MPa}$ and $40 \mathrm{GPa}$, respectively (Gale 1975).

The radial flow model for the laboratory experiments is shown schematically in Fig. 3. Two specimen diameters were used: $0.15 \mathrm{~m}$ and $0.95 \mathrm{~m}$. A compressive load was applied to the unconfined $0.15-\mathrm{m}$ specimen using an 80-ton Riehle testing machine. A special triaxial test cell (shown in Fig. 4) was used to apply a compressive load and a boundary water pressure to the $0.95-\mathrm{m}$ specimen. Once steady flow of water was established for a known normal stress across the fracture, an apparent aperture was computed using Eq. 3, ano $\mathrm{K}_{\mathrm{f}}$ could then be determined from Eq. 2. Inasmuch as the 0.95-m core could be completely enclosed, the water pressures could be controlled so as to have either divergent or convergent flow across the fracture surface. 


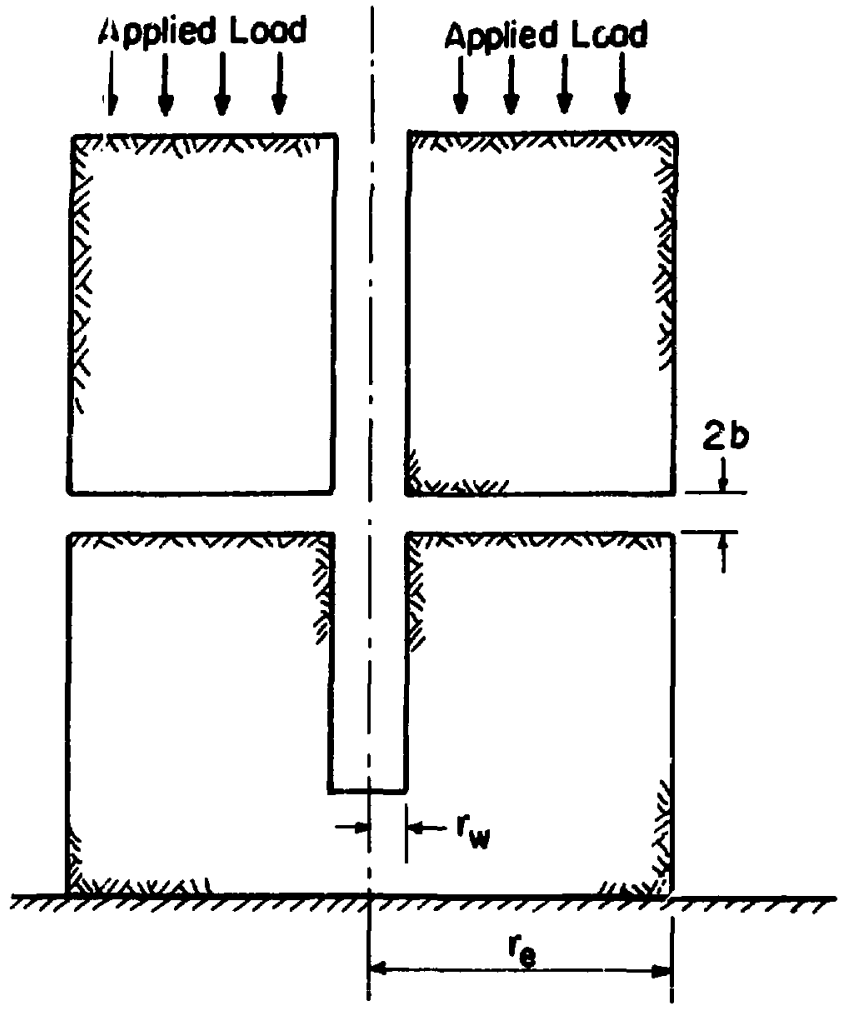

Fig. 3. Radial flow model for laboratory experiments on a horizontal fracture.

(XBL 7811-12802) 


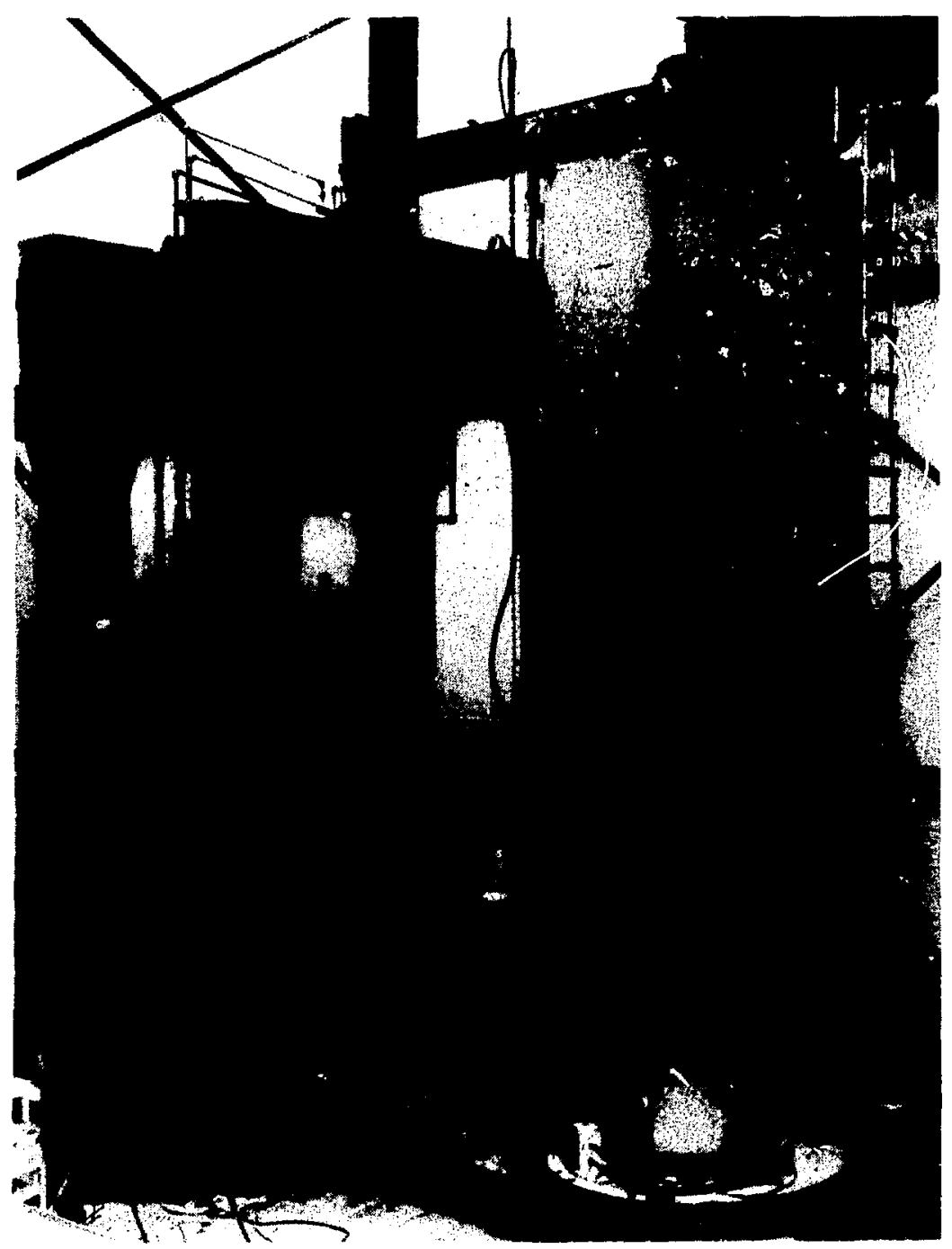

Fig. 4. Large-diameter core ready for assembly in triaxial cell. (XBB 753-1977) 
The in situ field tests were carried out by Pratt and colleagues at a field site in southeastern Wyoming where a number of investigations were made to determine the in situ properties of Sherman granite (Pratt et al. 1977). The permeability tests were made using two vertical boreholes that were drilled about $1 \mathrm{~m}$ apart along a vertical fracture. Stress across the fracture was controlled by flatjacks inserted in deep vertical slots cut parallel to the fracture and on either side. Hydraulic inflation of the flatjacks was used to change the stress levels on the fracture area $\left(1 \mathrm{~m}^{2}\right)$ exposed between the two boreholes. Once steady flow of water was established, an apparent aperture was computed using $\mathrm{Eq} .4$, and $\mathrm{K}_{f}$ could then be determined as before.

Boundary conditions used during the various tests are summarized in the table. The normal stresses shown in this table are defined as the total load across the fracture divided by the cross-sectional area. The exact area of contact within the actual fracture as well as the distribution of fluid pressures across the fracture are unknown.

Boundary conditions used in tests on hydraulic properties of fractures.

\begin{tabular}{|c|c|c|c|c|c|c|}
\hline \multirow[b]{2}{*}{$\begin{array}{l}\text { Specimen } \\
\text { type }\end{array}$} & \multirow[b]{2}{*}{$\begin{array}{c}\text { Fracture } \\
\text { area } \\
\mathrm{m}^{2}\end{array}$} & \multirow[b]{2}{*}{$\begin{array}{c}\text { Maximum normal } \\
\text { stress } \\
\mathrm{MPa}\end{array}$} & \multicolumn{3}{|c|}{ Hydraulic head } & \multirow[b]{2}{*}{ Flow type } \\
\hline & & & $\begin{array}{c}h_{w} \\
m, H_{2} \mathrm{O}\end{array}$ & $\begin{array}{c}h_{e} \\
m, H_{2} O\end{array}$ & $\begin{array}{l}h_{w}-h_{e} \\
m, H_{2} 0\end{array}$ & \\
\hline In situ & 1.00 & 8.7 & 41 & 0 & 41 & Linear \\
\hline $0.95 \mathrm{~m}$ & 0.71 & 12.0 & 0 & 36 & -36 & $\begin{array}{l}\text { Radial } \\
\text { convergent }\end{array}$ \\
\hline $0.95 \mathrm{~m}$ & 0.71 & 12.0 & 179 & 36 & 143 & $\begin{array}{l}\text { Radial } \\
\text { divergent }\end{array}$ \\
\hline 0.15 & 0.02 & 20.5 & 19 & 0 & 19 & $\begin{array}{l}\text { Radial } \\
\text { divergent }\end{array}$ \\
\hline
\end{tabular}

Note: From Pratt et al. (1977). 


\section{DISCUSSION OF RESULTS}

Results of the permeability tests are shown in Fig. 5 to demonstrate how the fracture hydraulic conductivity for these three rock specimens varied with increasing normal stress across the fractures. For the purposes of these investigations the conductivities of the intact rock are so small that they can be neglected. Note that $\log K_{f}$ is plotted versus $\log \sigma$ on Fig. 5 .

One may observe that in no case could the fractures be completely closed during the course of these experiments. This is apparent from the fact that each curve is at or approaching zero slope at some stress, which suggests that a limiting aperture was present in each case. Note that this limiting value of fracture conductivity increased with spec imen size.

The results on Fig. 5 would seem to indicate that the determination of fracture conductivity may be significantly influenced by a size effect. Part of the problem is that one must give due consideration to the amount of contact area within a fracture. This contact area supports the normal loads across the fracture and thereby reduces the open space through which flow takes place. With increasing sample size, we visualize that the contact area, expressed as a percentage of the total fracture area, reaches some average value for a given fracture, as shown in Fig. 6. As the area of the fracture increases so as to fall within region $B$ on this figure, the distribution of contact poinis is such that if one were to take any random sample of appropriate size within the fracture, the amount and distribution of contact points would be similar to that of any other random sample of similar size. 


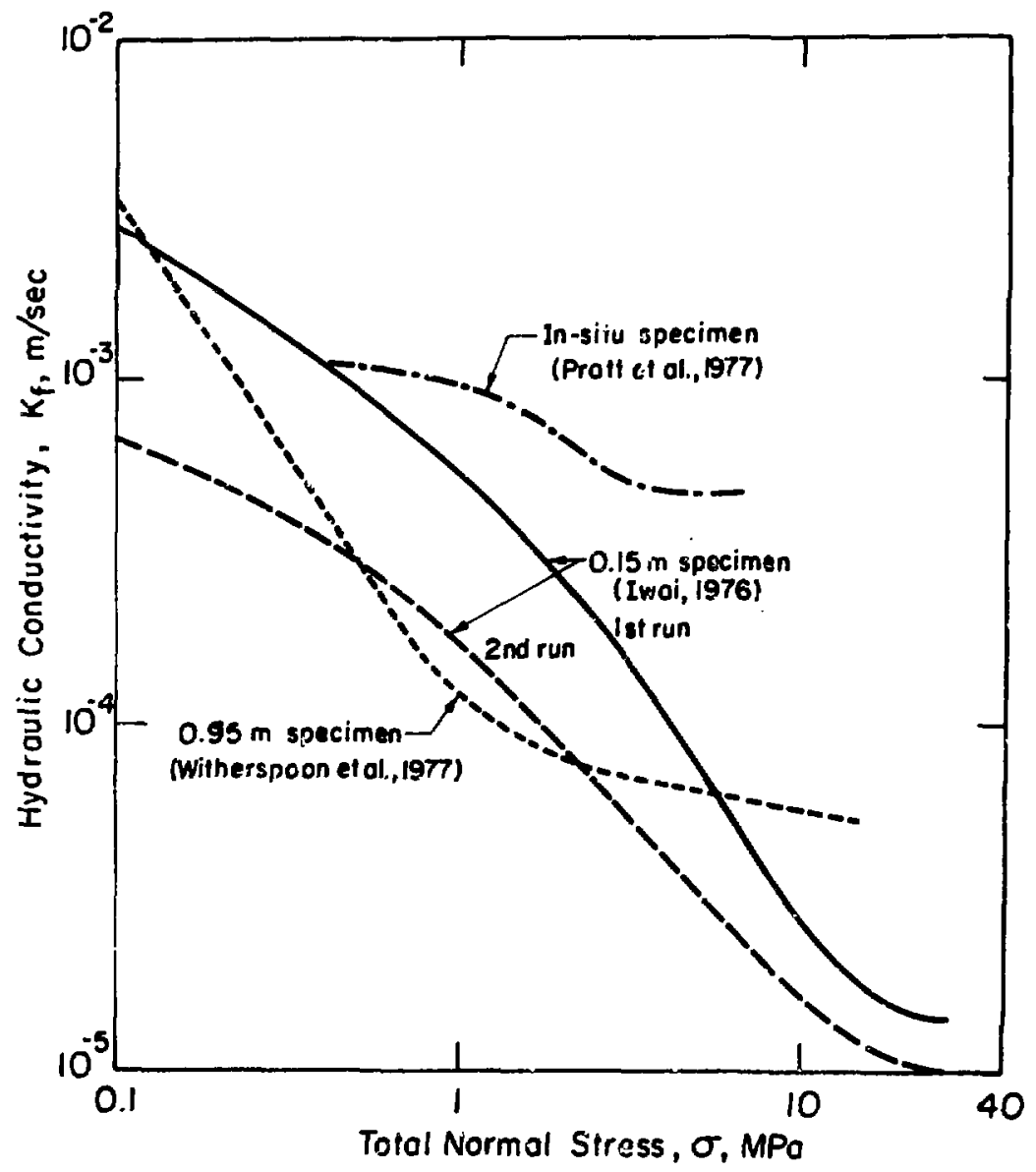

Fig. 5. Variation of hydraulic conductivity in a fracture with increasing stress for three different-size rock samples. Results for the $0.15-\mathrm{m}$ and $0.95-\mathrm{m}$ specimens are with radial divergent flow. Results for the in situ specimen are with linear flow. 


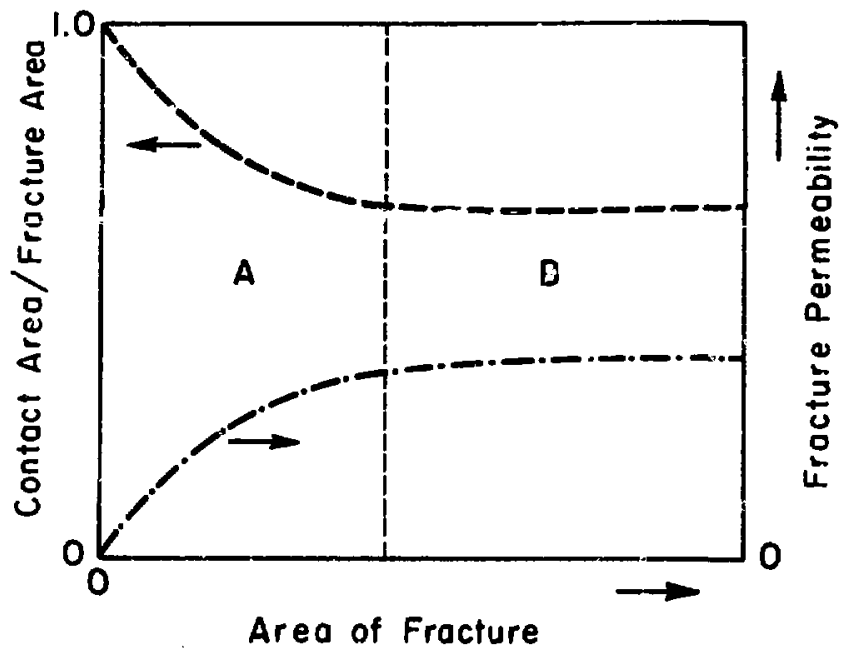

Fig. 6. Efisc of contact area on fracture permeabiiitity.
(XBL 785-508,8)

The similarity of thes:e random samples would also be reflected by the force-displacement curves for each sample being essentially the same.

Within region $A$, on the other hand, a variation in the flow channels can exist that apparentiy is caused by a variation in the percent contact area as we 11 as its distribution over the fracture surface being tested, This could yield significant variations in fracture permeabilities within region $A$ at any given stress level. Thus, we would expect that as sample sizes approach those of region $B$, the permeability of a fracture more closely approaches the true value for the existing stress level.

Another consideration is that as specimen size increases, the possibility of a mis-match occurring because of the combined effects of very slight shear movements and the inherent asperities that persist 
on any fracture surface can act to prop the discontinuity open. We recognize that perfect alignment of the fracture surface using the 0.95-m rock core, which weighs about 4 tons, may not have been obtained in the laboratory, and this may have contributed to the differences reported here. On the other hand, slight shear movements are likely to occur in fractured rocks, especially when man-made openings penetrate such systems. The problem then becomes that of deciding what size rock sample should be taken to the laboratory when fractures control the fluid moveme it.

The situation with regard to the (in situ) fracture work of Pratt et al. (1977) also needs attention. In this case, the pre-existing fracture '?d been exposed to weathering and undoubtedly some unknown shear movemelit could have occurred. In addition, the vertical fracture extended downward some unknown depth below the rock block being tested and its degree of interconnection with other fractures as well as the roughness are also unknown. Thus, the flow field and boundary conditions were not well defined. This is an unavoidable problem in field work and could explain why the hydraulic conductivities could not be decreased to the same levels as those observed in the laboratory work. An additional factor is that the granites tested in the field and in the laboratory were not the same. A better comparison of in situ and laboratory methods of measuring the stress effects on fracture permeability is needed.

\section{CONCLUSIONS}

The implications of these fracture flow studies on rocks of different dimensions are important. If our first results with an ultralarge 
core and the in situ work of Pratt et al. (1977) are more incicative of the flow behavior of a fracture in the field under stress, then further work on the question of specinien size is needed. Cores collected in the field are normally not larger than $0.15 \mathrm{~m}$ in diameter. However, the results of this work suggest that when this size core is used for fracture permeability investigations, the results may be significantly lower than will be found in the field. When the question of a "tight" formation arises, as is now the case in developing underground waste repositories, it is important that representative formation permeabilities be established. The results of our work suggest that where laboratory data are deemed necessary, more work is needed to determine optimum specimen size so that reliable results on flow in fractures under stress will be avai? sble.

\section{ACKNOWLEGMENTS}

This research was supported by the U.S. Geological Survey under Contract Number 14-08-0001-14583, the National Science Foundation under Grant Number GK-42776, and the U.S. Department of Energy under Contract W-7405-ENG-48.

\section{REFERENCES}

Bear, J. 1972. Dynamics of Fluids in Porous Media. New York: Amer. Elsevier Publishing Company. Gale, J. E. 1975. A Numerical Field and Laboratory Study of Flow in Rocks with Deformable Fractures. Ph.D. Thesis, University of California, Berkeley, $255 \mathrm{pp}$.

Iwai, K. 1976. Fundamental Studies of Fluid Flow through a Single Eracture. Ph.D. Thesis, University of California, Berkeley, 208 pp. 
Louis, C. 1969. A Study of Groundwater Flow in Jointed Rock and its Influence on the Stability of Rock Masses. Imperial College Rock Mechanics Research Report No. 10, September 1969. Noor ishad, J., P. A. Witherspoon, and T. L. Brekke 1971. A Method for Coupled Stress and Flow Analys is of Fractured Rock Masses. Geotechnical Engineering Report No. 71-6, University of California, Berkeley.

Polubarinova-Kochina, P. Ya. 1962. Theory of Groundwater Movement.

Translated by J. M. R. Delliest. Princeton, New Jersey: Princeton University Press.

Pratt, H. R., II. S. Swolfs, W. F. Brace, A. D. Black, and J. W. Handin. 1977. El astic and Transport Properties of In-Situ Jointed Granite. Int. J. Rock Mech. Min. Sci. and Geomech. Abstr. 14:35-45. Snow, D. T. 1965. A Parallel Plate Model of Fractured Permeable Media. Unpublished Ph.D. Dissertation, University of California, Berkeley. Witherspoon, P. A., C. H. Amick, and J. E. Gale, 1977. Stress-Flow Behavior of a Fault Zone with Fluid Injection and Withdrawal. Mineral Engineering Report No. 77-1, Iniversity of California, Berkeley. 